\title{
GLIMPSES OF MEANING: ABORIGINAL LITERATURE AND WESTERN AUDIENCES
}

\author{
LIANA FITZGERALD \\ University of Bucharest, Romania
}

\begin{abstract}
One of the most subtle and complex oral literatures, Australian Aboriginal literature, still keeps meaning covert to Western readers, despite its ever-growing popularity and prolificity. As an introduction to an ongoing research into orality in Australian Aboriginal Literature, this paper aims to focus on a number of reasons which, while make Aboriginal stories more palatable for Western culture, distil original meaning of concepts, beliefs and traditions. In other words, what are some of the elements which hinder source - reader communication when it comes to Australian Aboriginal literature? The focus of this paper is meaning transformation through layers of interpretation, starting from an original performance of a story, with its syncretism of art forms. It is well worth it to explore such development of meaning, from performance to oral translation into English, with its later written form, to ultimately broken-down fragments covert within poems or novels. It is of no wonder Western readership comes up against difficulty in grasping meaning from Australian Aboriginal literature, as our own understanding of universal concepts, such as time, space, spirituality is so fundamentally different. There are, however, valuable lessons to be learnt and any effort will yield reward.
\end{abstract}

Keywords: audiences, receptive processes, meaning distortion, Australian Aboriginal literature, Western readership

A most subtle and complex literature of long-standing oral and performative tradition, Australian Aboriginal literature still keeps meaning covert to Western readers, despite its ever-growing popularity and prolificity. As an introduction to an ongoing research into changes in oral techniques in Australian Aboriginal Literature, this paper aims to focus on a number of instances in which initial meaning of concepts, beliefs and traditions becomes diluted, distilled or 
distorted over time, under the shaping power of ever changing historical, sociopolitical contexts. Further, the paper includes a number of reasons which, while making Aboriginal tales more palatable for Western culture, lead to distortion of meaning, thus in fact hindering Indigenous source - non-Indigenous reader communication when it comes to discovering Aboriginal culture through literature. A main cause for meaning dilution worth considering is the reluctance with which Aboriginal sources share their knowledge, their stories, beliefs and traditions. A closer look into reasons for this reticence will reveal the expected cultural taboos and great respect for tradition, but also a justified concern for foul play. Although more and more genres arise and become established within Australian Aboriginal literature, it has been a constant struggle for authors to find a clear voice, and furthermore one which would be heard. This is especially if we consider the constant battle for recognition and the need for texts to serve mainly political purposes for decades on end, or to position writing in relation to the politics of life itself. The last reason to be discussed for Western readers to come up against difficulty in grasping meaning in Australian Aboriginal literature is our own understanding of universal concepts, such as time, space, spirituality. Our views are so fundamentally different, it is of no wonder we only struggle to catch glimpses of meaning. There are, however, valuable lessons to be learnt and any effort will undoubtedly yield reward.

As a preliminary setup, it is worth considering that the very concepts of time and history could instantly widen a gap between Aboriginal and Western cultures. Mindsets and cultural beliefs differ greatly, so it is essential to establish a common ground approach from the very beginning; one which would in turn lead to valid readings of certain Aboriginal literary works. Once established, such a methodology will combine historical and cultural contexts, reiterate the fact that Western views are (as well) largely cultural products rather than given truths, and open a series of short case studies based on key Aboriginal authors and their respective intentions, to a Western readership. The goal of this preliminary undertaking is to focus on concepts of time and history in such a way as to remove non-Aboriginal readers from culturally appropriated concepts, in order to bring them closer to the core meaning of those concepts, as illustrated in Aboriginal texts. Chosen, not entirely unwillingly, in chronological order, the texts range from David Unaipon's Legendary Tales of the Australian Aborigines, published in 1930 and only much later recognised as the first book written by an Aboriginal author, to Oodgeroo Noonuccal's poetry collection We Are Going - the first volume published by an Aboriginal female writer in 1964, to Kevin Gilbert's powerful political novel Because a White Man'll Never Do It, published in 1973 and Sally Morgan's canon challenging work, My Place, published in 1987. All mentioned works reveal auctorial intentions which aim at appealing to Western sensibilities in such a way as to bridge communication channels and aid collaboration between the two cultures. 
It is worth mentioning that culturally speaking, concepts such as time and history are rather linear constructs in Western thought. As Rebecca Walker mentions in her article Eternity Now: Aboriginal Concepts of Time, "Western culture has become so adept at identifying itself with the scientific method and empiricism that it can be difficult for us to realise that our understanding of time is culturally appropriated" (Walker n. pag.). Going back to the Aboriginal view, it is important to understand the permanence of actions in time, as "[t]he continuity of history is understood in social terms, through links to ancestors and descendants." (Walker n. pag.) An event in history is not reduced to the one single past instance, but it has permanent reverberations through future generations. To provide a telling example,

The re-enactment of an event in Aboriginal culture is seen as equivalent to the original event. For example, in re-enacting the story of the Passion of Christ, some elders said they did not like the ceremony, and were considering stopping it. A Walpiri man said that it "made him sad to keep on killing God." "Instead of merely dramatically portraying a historical event, the crucifixion was, to some Warlpiri, if not all, a contemporary reality.” (Walker n. pag.)

This would be a useful angle through which to perceive temporal and historical aspects in Aboriginal culture. Duration and chronology have less to do with the passing of time, than persistence of action, which lingers in time and has endless reverberations across spaces and generations.

Thus, already with a view of temporal and historical aspects closer to the one portrayed in Aboriginal literature, a series of short case studies on how nonIndigenous audiences have received Aboriginal literature over time will reveal auctorial intentions towards acceptance and communication and a gradual understanding and raise in interest in literary works. It is necessary to put things in perspective using support materials which follow a global approach based on comparisons rather than a set familiar framework, such as C.A. Bayly's The Birth of the Modern World, 1780 - 1914, which "insists on the importance of the activity of the colonised or semi-colonised non-European peoples” (Bayly 2); or more targeted works, such as the volume First Australians, edited by Rachel Perkins and Marcia Langton, in which all contributors are either of Aboriginal descent or have worked closely with Aboriginal communities, and can present historical facts from an encompassing cultural perspective. Finally, Adam Shoemaker's Black Words White Page, a comprehensive analysis of Aboriginal literature until 1989, brings clarity when overlapping literary works with historical contexts. 
Before moving on to a series of literary case studies, it is essential to pause and give thought to how the first years of post-contact history shaped Indigenous nations and their relations with the colonizing forces.

[T] he indigenous populations of North America and Australasia and the Pacific [...] provide many examples of nomadic, forestdwelling, and hunting populations. These were culturally sophisticated, linguistically diverse, [...] closely tied to the cycles of natural and animal world [...]. Religious activity centred on cults and mysteries rather than on preaching and regular ritual. The culture shock generated amongst such people by the sudden arrival of missionaries and European military units or administrations is difficult to exaggerate. (Bayly 39)

The ripple effects of the mentioned shock wave, across generations of Aboriginal communities, will become readily accessible through a few examples of literary works which mark changes in attitude, concept rendition, audience choice, and reception processes.

To start with, here is a partial representation of a Dreamtime story, ${ }^{32}$ performed at the Australian Museum in Sydney. ${ }^{33}$ At a first glance, it might seem a rather basic tale, especially because in essence it is meant for a young audience. However, it is worth considering that, as author and storyteller Helen McKay suggests in a vivid manner, meaning in Aboriginal stories reveals itself much like an onion when peeled. Even short renditions such as this one, encompass "twenty or more lessons [which] can be found in a single story, teaching such subject matters as: the spiritual belief system, customs, animal behaviour and psychology, land map of the region, hunting and gathering skills, cultural norms, moral behaviours, survival skills and food resources” (McKay n. pag.). Certainly, a general Western readership is here almost completely in the dark. With no more than a few hand gestures which help carry narrative elements, and one's personal sensitivity to rely on, any attempt to extract meaning quickly proves to be an arduous undertaking, in fact heavily reliant on translation. The manner in which storytellers switch between English and their respective Aboriginal languages during the performance cannot be classified as a matter of translation; it is rather a matter of bilingualism as a form of

${ }^{32}$ Dreamtime is part of the Aboriginal cultural and religious worldview. However, "[t]ime is not part of the semiotic meaning of the [Aboriginal] 'Aranda' word, thus the original English translation 'Dreamtime' is often replaced by the term 'Dreaming'. [...] Dreaming refers to the religious world view of Aboriginal culture in general, whereas 'Dreamtime' refers specifically to the time of creation.” (Rask Knusden 5)

33 The following video was played during the conference presentation: https://youtu.be/J4rAa6PReQM 
hybridisation, as Homi Bhabha conceptualizes it. From Anthony Pym's analysis of Bhabha's theory as part of his cultural translation basis of premises, "[w]hat we have, though, looks more like a diffuse kind of longing ("to dream") that comes from the position of a translator, situated on or perhaps in the borders between cultures, defined by cultural hybridity" (Pym 146). However, certain fragments of translation help construct sense around what the legend is roughly about, the importance that sound, song and performance have for the Aboriginal culture, but this in itself does not naturally offer immediate access to the deeper multitude of meanings it encompasses. It will become evident in the paragraphs to follow that Aboriginal literature written in English most likely provides a more comfortable medium for exploring meaning at a global level. On the other hand, this does not guarantee a full and valid emersion in Aboriginal culture.

David Unaipon's Legendary Tales of the Australian Aborigines was the first book written in English by an Aboriginal author. Due credit of authorship was given much later, as it was firstly attributed to anthropologist W. Ramsay Smith and published under his name. When Stephen Muecke and Adam Shoemaker restored and repatriated the text in 2001,

they also discussed the nature of custodianship in Aboriginal
knowledge systems. [...] Foundational Aboriginal writers often
worked in cooperation with a non-Aboriginal person drawn from
their circle of friends and acquaintances. Significant textual
compromise was often the price Aboriginal authors paid for the
assistance of these collaborators. (Jones 37)

This offers essential insight into a number of facets. Firstly, as mentioned, the concept of authorship in Aboriginal culture comes down to custodianship, a collective ownership of songs and tales from different regions. Custodianship refers to a temporary ownership of cultural aspects, instead of having permanent, individual ownership, the storytellers are merely their repeaters. The 1930s were a time when "Aboriginal people throughout Australia were invariably hit harder by the Depression, and took longer to recover from its hardships, than the white citizens of Australia" (Shoemaker 18) and "[o]ne of the effects of the great depression, all over Australia, seems to have been a more rigid containment in institutions, where conditions were probably worse than ever before, with enduring effects on Aboriginal attitudes" (18-19). These rigid conditions surfaced in policies and practice because, while at the time "White Australians held numerous and often conflicting views of Aborigines, ranging from the sympathetic and humanitarian to the violently racist and bigoted, [...] almost everyone agreed on one point: the Aboriginal people were a race doomed to extinction" (20). These attitudes soon translated into segregation policies, some of which with shattering effects, spreading trauma over generations. It is 
of no wonder then, Unaipon collaborated in his work with British partners, even to the point of having his work published under a different author's name.

This misappropriation is also closely related to the reception process of the literary work. It would have indeed been extremely difficult, if not impossible, for an Aboriginal author at the time to publish any type of work without the help of British collaborators. Moreover, an Aboriginal author on the cover of a book would have made the volume far less appealing to the nonIndigenous audience and its dissemination would have been stifled from the very beginning. As Shoemaker remarks, "the achievements of the first Aboriginal writer in English, David Unaipon, who published in the 1929-1945 period, were almost totally ignored until the 1970s and still deserve far more study than they have received" (41). Fully aware of these aspects, and as an Aboriginal man completely immersed in British culture and Christian education, David Unaipon not only made his decision about how the book would be published, but the style in which it is written also makes the text quite ready for compromise, as Jones describes it. Although Unaipon sets a series of Aboriginal tales on paper, he does so in quite a scholarly and sermon-like manner, he explains concepts before diving into the legends, as for an uninitiated audience. There is also a heavy Christian influence in all stories, which makes their style quite eclectic, but easier to grasp and appealing to a non-Indigenous readership. It is worth mentioning at this point that Unaipon was most probably writing exclusively for a non-Indigenous audience. As one of the very few Aboriginals to not only survive but even thrive in the mission system, Unaipon's writing, and speeches in general, mark a clear delimitation between himself and the rest of his people, where he feels he benefited greatly from access to the European civilisation. He stresses this quite often when addressing Aboriginal audiences and is militant for an Indigenous - non-Indigenous cooperation and collaboration where Aboriginals are to follow the latter in their civilised way and subdue, if not renounce, their tribal heritage. Poet and activist Kevin Gilbert sheds more light on the matter in his powerful take on Aboriginal post-contact history, Because A White Man'll Never Do It,

Not only did the Aborigine lose his pride, his place and his identity but group distinctions began to intrude to complicate the situation yet further. The mission blacks were taught by missionaries to deny their 'animal nature.' [...] On the other hand, the tribally identified remnants sneered at these imitation blacks who bashed the bible to please the white fornicator who 'controlled their animal nature' but rarely his own. [...] So the distinctions increased — the distinctions between government reserve blacks, church blacks, fringe-dwelling blacks and partassimilated town blacks who looked down on what they regarded as their more backward brothers. (Gilbert 14) 
Coming back to Unaipon's auctorial intentions, the compromise here is also strategic. As Muerke and Shoemaker note in the edition's introduction, Unaipon's is "a pattern of writing reflecting a pattern of escape from European institutional control, where the very act of collecting and writing stories certain types of stories - became Unaipon's passport away from the constraints of the mission system in the 1920s" (Unaipon xii). In a period when, as Shoemaker bluntly phrases it, "the reigning popular view of Aborigines was that they were somehow sub-human, both intellectually and culturally inferior to whites" (19), Unaipon manages to bring to the front, even if only on the fringes, in the mission system, fragments of Aboriginal culture, unafraid of embracing and using the coloniser's religious views, culture and academic props. His literary fragments are only part of his works, as he was also a brilliant inventor, an intellectual, and musician. With or without his own anticipation of the effects of his writing, at least half a century later, Western audiences already more educated and sensitive towards non-Western cultures, were taking a much keener interest in the first Aboriginal author to write in English. What is interesting to know in terms of audience reception of Aboriginal work, is that in the 1970s, tales much resembling Unaipon's own renditions, were being published in reading booklets for schools. Such is the case of Travelling On, compiled by the Infants' Reading Committee under the authority of the Minister of Education and illustrated by Katherine Morris. The booklet contains at least two Aboriginal tales, albeit their introduction still bears a rather racist tone.

By the 1960s, a series of rapid changes in individual and group attitudes, legal policies, socio-political contexts were catalyst for deep, complex changes within and a greater output of Aboriginal literature. This was a time when the Federal Council for the Advancement of Aborigines and Torry Strait Islanders was becoming both more visible and more vocal in promoting welfare and civil rights for Aboriginal communities, when highly influential movements such as the "Freedom Rides" were organised at state level, and wage parity was at least being discussed, subsequent to heavy strike actions. As such the decade was ripe for activist literature and the emergence of authors resolved to provide a voice for their communities.

At the same time that Noonuccal was preparing her first books of poetry, important socio-political changes were altering the status of Aboriginal Australians. [T] he decade beginning in 1960 was one of protest, publicity and, in some cases, significant change in the realm of Aboriginal affairs. This is not to say that the autonomy or the political influence of Black Australians increased evenly throughout the entire country. (Shoemaker 6) 
Oodgeroo of the Noonuccal tribe $(1920$ - 1993) is an influential figure on the Australian Aboriginal literary, political and cultural scene in the second half of the twentieth century. Her poetry is heavily activist, and she is considered the first modern Aboriginal protest writer. We Are Going (1964), her first volume of poetry, is also the first book to ever be published by an Aboriginal woman. Her poems manage to blend a sloganizing and polemical discourse, which constantly evokes the traumatic dispossession of the Aboriginal people, with the warmth of a voice which, while keeping close to tradition by using easily accessible rhyme schemes, sends a heartfelt, hopeful message for the future, which is also palatable for Western audiences. As a marked distancing from Unaipon's work, she uses her writing to address both her own people and the coloniser, in a way in which she opposes radical alterity through a prophetic hopeful message, by refusing to merely promulgate oppositions.

Before moving on to her poetry, it is important to first lay some groundwork and give reading to the context to her life, pinpoint certain key milestones, in order to better understand the message of her writing. One such key milestone, which goes a long way into explaining the close relation of the author's life, heritage and literary work, has to do with the author's name. As Jean Baudrillard mentions in the second chapter of Radical Alterity - The Other, Somewhere Else - "Western societies reduced the reality of the Other through colonisation or cultural assimilation" (Baudrillard 34). One basic way of fundamentally immersing a society in the colony's reality was to re-write identity by giving out different names. C.A. Bayly sets this in a historical context related to a growing global uniformity:

Another consequence of growing global uniformity can be seen in the practice of naming. Personal names became more standardized as printed media and movements of religious and cultural change spread across societies, erasing differences in local naming patterns. [...] Christian evangelization spread European "Christian" names, most themselves once Jewish, of course, to millions of Africans, American Indians and dwellers in the Pacific in the course of the nineteenth century. (Bayly 18)

In Australia, as in most other colonies across the globe, names were changed by employers or missionaries or when a child was forcibly removed and placed in foster care. The writer was born under the name Kath Walker. In school she became literate in the coloniser's language which she later used to make her message heard, having to constantly negotiate between the inherited core of beliefs of oral expression, and the shape of the language it all had to be transformed (rather than translated) into. Much like Unaipon's, hers was a life closer to the European Australian culture than her own heritage. Unfortunately, with uprooting communities and separating individuals came not only a sense of 
unbelonging and confusion, but also of ambivalent feelings towards Aborigines' own heritage. This becomes clearer from Kevin Gilbert's raw perspective:

The transfer of their attitudes and values to their black servants led to intense feelings of shame on the part of the blacks. Much of this shame survives today. It can be seen in the poetry of Kath Walker who, though feeling that her ancestors were inferior to the clever white man, nevertheless struggles to identify herself with the underdog. (Gilbert 16)

However, throughout her life and through her writing Noonuccal manages to grow closer and closer to her heritage. As noted in A Difficult Position, Between Worlds, a chapter dedicated to Oodgeroo's writing in Feminist Poetics of the Sacred-Creative Suspicions,

In 1988, the bicentennial year of white settlement of Australia, the then Kath Walker changed her name to Oodgeroo of the Noonuccal tribe [...]. This act disturbed some observers, who failed to understand the symbolic power of such an act. And symbolic, prophetic power - of words, of storytelling, of relationship with the land, of myth, of tradition - was what Oodgeroo drew on in her negotiations with white Australia." (Devlin-Glass 78)

A simple gesture heavy with symbolism marked Oodgeroo's return to self, to the culture and traditions of her people, which made her surround herself with authenticity. "In her words, 'I have renounced my English name because the House of Commons and Lords in England have neglected us for 200 years. They could not spell the Aboriginal names, so they gave us English ones'." (Shoemaker 246)

As already mentioned, Oodgeroo made use of the coloniser's language to make her message heard; a message not hardened in a monolithic position, but flexible and volatile between her two target audiences. Moreover, it was Oodgeroo's hope that in doing so she will provide her people with a communication bridge which would help them express their own voice and make themselves understood, heard and seen. In Municipal Gum she exposes the dire effects of colonisation, through a metaphor which brings into play the Aboriginal spiritual, physical, social and cultural connection to nature in a context which is more familiar to non-Indigenous audiences.

Gumtree in the city street,

Hard bitumen around your feet,

Rather you should be

In the cool world of leafy forest halls 
And wild bird calls.

Here you seem to me

Like that poor cart-horse

Castrated, broken, a thing wronged.

Strapped and buckled, its hell prolonged,

Whose hung head and listless mien express

Its hopelessness.

Municipal gum, it is dolorous

To see you thus

Set in your black grass bitumen -

O fellow citizen,

What have they done to us? (My People 45)

Finally, why is it that Oodgeroo's message takes on a prophetic quality and how does this involve her refusal to promulgate oppositions? As mentioned in Feminist Poetics of the Sacred, if a prophetic state is reached by portraying matter so precisely that it leads to an enabling of spirit, then this was the circumstance which Noonuccal capitalised, by making use of the oppressor's tools to give her own people "their voices, their hopes, their inspirations, their frustrations, their aspirations." (Devlin-Glass 79). Hopeful that her message would reach both worlds, "Oodgeroo uses a range of rhetorical and ideological weaponry as she constructs and inhabits this [...] cultural reality, seeking the ear of her people and the ear of the coloniser: dialogue, irony, sarcasm, lament, diatribe, protest and rallying cry [...]" (79). Oodgeroo's carefully crafted message is meant to vibrate into the core of both her people and of nonIndigenous Australians, and the powerful imagery in her stanzas often demand action and cooperation. One such example is the last stanza in The Dispossessed, which stands carefully apart from the rest of the poem, creating that momentary pause ripe for reflection.

[...] When Churches mean a way of life, as Christians proudly claim,

And when hypocrisy is scorned and hate is counted shame, Then only shall intolerance die and old injustice cease, And white and dark as brothers find equality and peace.

But oh, so long the wait has been, so slow the justice due, Courage decays for want of hope, and the heart dies in you. (My People 62)

Oodgeroo, through her poetry, stands apart from the single position of radical opposition. Rather, she refuses to merely promulgate oppositions, and focuses on reaching both audiences, creating a bridge between them, and sounding out a heartfelt call to cooperation and empathy. Not only this, but she is clearly the 
pioneer of a cultural and literary movement, more cohesive in thought, attitude and style.

\begin{abstract}
Hence, when Oodgeroo Noonuccal's first collection of poetry appeared in print in 1964, a new phase of cultural communication began in Australia. Not only the content, but the very fact of Noonuccal's We Are Going was important as, effectively for the first time, one of those best qualified to do so was commenting creatively upon her own race, its aspirations and fears. (Shoemaker 5)
\end{abstract}

As Shoemaker observes, Noonuccal's poetry, published and widely disseminated, marked the beginning of "self-reflective literary examination"(5) by Indigenous writers. Perhaps even more importantly, through her verse Aborigines started to express their views on White Australians. Moreover, Oodgeroo pioneered an era in which Western audiences started to pay more and more interest in Indigenous literature. Her books were not only read widely across Australia but translated into quite a few European languages and used as more than simple literature, but as pedagogical instruments.

The shift from Oodgeroo of the Noonuccal tribe to Kevin Gilbert, in terms of their activity both in the cultural and socio-political areas, is not a difficult one to make. Both prominent figures of their respective generations, both prolific and influential, they follow one another naturally on the Australian Aboriginal cultural scene: "Noonuccal thus established what might be termed the 'representative' school of Aboriginal poetry, an approach which has attracted other notable Black Australian poets, such as Kevin Gilbert” (Shoemaker 186). One major discrepancy between the two can be easily observed in their attitude and literary style. While Oodgeroo's is a tamer approach, calmer, more feminine even, which aims towards cooperation, Gilbert's is a more incisive, demanding attitude. His literary work has quite a bit more bite, which makes his writing at times uncomfortable for either of the two audiences he addresses. "Kevin Gilbert considers this to be unavoidable, and he feels that Aboriginal writers should not shy away from examining the past, even if it produces resentment” (Shoemaker 120).

In 1973, Kevin Gilbert (1933-1993) lives up to his heritage as warrior of the Wiradjuri tribe and releases a firm, biting account of the Aboriginal fight for land, demanding action. Because a White Man'll Never Do It is a combination of verse, poetry, speeches and essays, all laced with the author's own life experience, which makes it difficult to box into a certain literary genre or category. Each chapter focuses on a theme or topic that is related to the history of Indigenous Australians and is prefaced by the author's own poetry. The text also contains a number of literacy and language techniques which remind the readership that Gilbert was an incredibly versatile writer, whose work ranged 
from political activist poetry, theatre plays, short stories to even love poems and nursery rhymes.

Just as with the first two case studies, it is worthwhile to set the historical and cultural context in which one of Gilbert's major works came to be. While the 1960s saw rather timid protests and scares achievement, the 1970s showed a great deal of progress both in attitude change - be it from the Indigenous or non-Indigenous population - and in practical achievements over Aboriginal claims. The positive self-image within Aboriginal communities was starting to soar, although it still suffered from the constant inconsistencies between promised legislative changes and practical advances in terms of welfare.

Though the 1961-1988 period was one of success in many fields, it was also one of frustrated expectations and hopes. Perhaps most importantly, the era saw the initiative for protest activity in Aboriginal affairs pass from white-dominated bodies to cooperative organisations, and then to groups controlled administratively - if not financially - by Black Australians. (Shoemaker 104)

Referring further to protest activity, Kevin Gilbert happens to be one of the founders of probably the most important symbolic protests towards Aboriginal land and freedom claims. The first Aboriginal protest to receive international coverage, the gesture was as simple as erecting a tent in front of the Parliament House in Canberra. To be more precise,
on 26 January 1972 (Australia Day) a group of young Black Australians erected a tent directly opposite Parliament House in Canberra, calling it the 'Aboriginal Embassy'. [...] The Tent Embassy was one of the most important symbolic gestures of black determination and defiance of the 1970s. (Shoemaker 111)

On more practical grounds, Gilbert contributed not only to the cultural and literary works of his community, but also developed major breakthroughs in terms of interracial communications. Thus, "Gilbert's ground-breaking contribution to the oral method, which showed just how much could be revealed by Black Australians responding to the questions of other Black Australians, [...]" (Shoemaker 132) was of paramount importance in collecting stories, tales, and life experiences first hand from Indigenous communities.

One of the results of his method can be seen in his work Because $a$ White Man'll Never Do It. The very title of the book is drawn from an interview with land rights activist Alice Briggs, which gives the book its call-to-action tone from the onset. 
The only answer is to give them back their land rights and let the Aborigine try and rectify what the white man has done, because a white man'll never do it. While ever he tries to tell an Aborigine what to do you're going to have the same thing all the way through life. And I for one don't want to see my kids grow up in the conditions that I've grown up in. And if the children of tomorrow are going to have a chance, it's not going to come from education. Certainly not. It's got to be handed back to our people to educate their kids in their own way - and educate themselves. And make a life for themselves - but not to be hounded by a white man and be told to do it, because he won't do it. (Gilbert 19)

The compilation of his own powerful verse with incisive interviews and real-life stories can leave the impression that Gilbert would be (anti-white) racist. This would be but a superficial view, while the true aim of his work is to reach both audiences, holding as fair a view on both as his position would allow, He does so with authenticity, employing the bitter tone which characterises an author whose ancestral heritage as well as personal life was one full of violence and struggle.

For he is just as critical of Black Australians who allegedly sell out their people by accepting European accolades or well-paid government employment, or by passive complacency. Some of the author's most trenchant verse is aimed at these supposed betrayers of the Aboriginal movement. (Shoemaker 195)

Instead of drawing a conclusion moving away from Kevin Gilbert's works, it would pay off more to draw a circle, or rather a spiral. ${ }^{34}$ A spiral from the days of the Wiradjuri Nation wars, in the area of Sydney at the beginning of the nineteenth century. Those were the days when, following misunderstandings and tension between the Indigenous and newly arrived European populations, martial law was declared by the British army against the Wiradjuri tribe. It is interesting to know that a few years before, one of the settlers, upon arrival was taken by the tribe to well-watered areas and, by learning the local language he was effortlessly able to maintain friendly relations even during the dire times to follow. It is the son of this settler, who, upon martial law being repealed after four months of massacres, gives an incisive conclusion of the atrocities in one of his reports: "When Martial Law had run its course extermination is the word most aptly describes the result. As the old Roman Tacitus said $<<$ they made a solitude and called it peace >>" (Langton 41). Through near extermination and every other hardship in between, the Aboriginal peoples of Australia have had to spiral back to their own selves. It is of hardly contestable importance that this be

\footnotetext{
${ }^{34}$ Reference to Eva Rask Knudsen's The Circle \& The Spiral - A Study of Australian Aboriginal \& New Zealand Maori Literature, Rodopi, Amsterdam, 2004.
} 
done, as can be extracted from Gilbert's interviews, in their own terms, by their own means. This means for any Western culture to be able to understand, learn from and support such endeavour, a clear vision of Aboriginal cultural concepts is paramount. The following passage from the Epilogue to First Australians should shed further light on the holistic and global approach to time and history Aboriginal culture holds:

Yet something of the vision of the men and women whose narratives run through our history has remained a part of Australian society. They are present in the pages of records, and their imprint on our cities and landscapes can be understood when we know their stories. Whereas William Suttor wryly cited the annals of Roman history in his remark at the end of the wars with the Wiradjuri - 'A solitude called peace' - history helps us to hear the voices of the First Australians in each place they inhabited. (Langton 250)

When it comes to identifying meaning cross-culturally through literature, at all to be neglected are also the "intricacies of the reception process" as prof. Rodica Dimitriu phrases it in her contribution to Pym's collection of essays Sociocultural Aspects of Translating and Interpreting. Although her focus is the reception of Defoe's Robinson Crusoe by the Romanian culture, she makes valuable theoretical statements regarding the contribution of translations to the reception process, which suit a broader range of contexts. In her own words:

The presence of foreign works in cultural repertoires testifies to complex receptive processes. These processes take place in different historical periods and involve operations of acculturation, accommodation, adjustment and refraction, which are all meant to ensure final acceptance of the foreign texts by inevitably different target cultures. As distinct modes of reception, translations play an important role in this process, and the discipline of Translation Studies can contribute valuable data to the history of the reception of foreign literature. (Dimitriu 73)

Firstly, Dimitriu mentions the different images of stories and heroes which translators tried to project onto readers over 150 years of reception, with the main aim of acceptance. This is a very delicate matter when it comes to Aboriginal literature, one which has two sides. On the one hand, non-Indigenous editors and translators distort original meaning out of the need and desire to introduce a culture to a type of literature which is remote in a multitude of aspects. On the other hand, Indigenous writers, in collaboration with Indigenous editors, work towards an intentional meaning dilution or distillation, in order to achieve the same end goal, which is acceptance, collaboration, communication. 
For the first case, there are examples of translations of Australian Aboriginal texts into European languages, extremely similar to the ones prof. Dimitriu recounts; where in the name of acceptance and ease of understanding, translators take quite a few liberties with the text, in detriment of the authors' original intentions. "The way these books are translated and marketed often distorts the author's original intentions and distorts how Australian Aboriginals are perceived by European communities" (Čerče 71). One such example, discussed by Danica Čerče and Oliver Haag in their essay European Translations of Australian Aboriginal Texts, is the case of Sally Morgan's My Place, translated into Slovenian by Tamara Bosnič. The discussion is lengthy, but to offer just one account of the distancing from original auctorial intentions, "the translator paid scant regard to Aboriginal English diction by using grammatically correct Slovene literary language [...]" (74). There is no doubt the task was a delicate undertaking from the very beginning, as "not only is the cultural repository contained in the original book somewhat problematic in a text addressing a Slovene readership; the source language, with its occasional departures from Standard English also presents difficulties" (74). Dimitriu's contention becomes then quite clear; borders between "translation proper" and "adaptation" are in reality blurry and much more flexible than might be admitted. In this case, the unfortunate result was most probably a distorted image of, for example, the figure of the grandmother, which in the Slovene version of the novel must not have gotten the chance to reveal to full extent her life story and trauma, the subtleties of her relationship with the other family members and her community.

Tracing back through the spiral, in lieu of a conclusion, it becomes apparent that while Sally Morgan's life writing enjoys an obviously increased interest at an international level, her (characters') voice more easily heard, it does so through the support of her predecessors. Thus, mentioning Oodgeroo's poetry it is worthwhile to remember that, while Gilbert's verse and prose had more power and incisiveness, it had the opportunity to do so because it spiralled up from her pioneering activist poetry. And while Oodgeroo had a more commanding voice and a more cohesive identity to offer through her writing, she did so because others before her, like David Unaipon, made use of the colonisers' language and academic props in order to hone tools which Aboriginal artists and activists could use to communicate and collaborate with European-Australians. Aboriginal culture ties its branches together in a syncretic form and uses its living history to send powerful messages towards a global audience. In turn, by becoming more detached from its own culturally constructed views and beliefs, Western readership is better able to create communication bridges which aid understanding and is more likely to purposefully read into and grasp Aboriginal cultural aspects. 


\section{References:}

Baudrillard, Jean and Marc Guillaume. Figuri ale alterității. Pitești: Paralela 45, 2002.

Bayly, C. A. The Birth of the Modern World, 1780 - 1914. Malden: Blackwell Publishing, 2003. PDF file.

Čerče, Danica and Oliver Haag. "European Translations of Australian Aboriginal Texts." Wheeler, Belinda ed. A Companion to Australian Aboriginal Literature. New York: Camden House, 2013. 71-74. Print.

Devlin-Glass, Frances, and Lyn McCredden. Feminist Poetics of the Sacred - Creative Suspicions. Oxford: Oxford University Press, 2001. PDF file.

Dimitriu, Rodica. "From Robinson Crusoe to Robinson in Wallachia." Pym, Anthony, et al., eds. Sociocultural Aspects of Translating and Interpreting. Amsterdam: John Benjamins Publishing Company, 2006. 73. PDF file.

Gilbert, Kevin. Because A White Man'll Never Do It. Sydney: HarperCollins Australia, 1973. E-book.

Jones, Jennifer. "Australian Aboriginal Life Writers and Their Editors." Wheeler, Belinda ed. A Companion to Australian Aboriginal Literature. New York: Camden House, 2013. 37. Print.

Langton, Marcia. "'They Made a Solitude and Called It Peace"." Perkins, Rachel and Marcia Langton eds. First Australians. Carlton: The Miegunyah Press, 2008. Print.

McKay, Helen. Australian Aboriginal Storytelling. n.d. Web. 15 April 2019. $<$ http://www.australianstorytelling.org.au/storytelling-articles/a-d/australianaboriginal-storytelling-helen-mckay>.

Oodgeroo. My People. Milton: John Wiley \& Sons Australia, 2008. Print.

Pym, Anthony. Exploring Translation Theories. London: Routledge, 2010. PDF file.

Rask Knusden, Eva. The Circle \& the Spiral A Study of Australian Aboriginal and New Zealand Maori Literature. New York: Rodopi, 2004. e-book.

Shoemaker, Adam. Black Words White Page - Aboriginal Literature 1929 - 1988. Canberra: The Australian National University E Press, 2004. PDF file.

Unaipon, David. Legendary Tales of the Australian Aborigines. Carlton: The Miegunyah Press, 2001. Print.

Walker, Rebecca. Eternity Now: Aboriginal Concepts of Time. Prod. The Salvation Army Australia Southern Territory Corps Programme Department. 27 August 2010. Web. 2 April 2019.

\section{BIONOTE}

Liana Popa Fitzgerald is a second year PhD student at the Doctoral School of Literary and Cultural Studies, University of Bucharest. Her doctoral research investigates orality in Australian Aboriginal literature, with a focus on how oral techniques have modified over decades, based on socio-political contexts. The project brings together works ranging from the first collection of legendary tales to be published, to the most recent novels by Aboriginal authors. An adjacent 
part of her interest, which stems from her career as an EFL professional, is the practical application of oral storytelling techniques in teaching methodology. 
